\title{
A Novel A33 Promoter-Based Conditionally Replicative Adenovirus Suppresses Tumor Growth and Eradicates Hepatic Metastases in Human Colon Cancer Models
}

\author{
Eduardo G. Cafferata, ${ }^{1}$ Daniela R. Maccio ${ }_{r}^{1}$ Maria V. Lopez, ${ }^{1}$ Diego L. Viale, ${ }^{1}$ Cecilia Carbone, ${ }^{3}$ \\ Guillermo Mazzolini, ${ }_{r}$ and Osvaldo L. Podhajcer ${ }^{1}$
}

\begin{abstract}
Purpose: A33 antigen is a membrane-bound protein expressed in intestinal epithelium that is overexpressed in $95 \%$ of primary and metastatic colorectal carcinomas but is absent in most epithelial tissues and tumor types. We hypothesized that A33 promoter might be useful in the design of a conditionally replicative adenovirus for the treatment of colorectal cancer (CRC). Experimental Design: We cloned an A33 promoter fragment (A33Pr) that extends from -105 to +307 bp. Using luciferase activity as a reporter gene, we showed that $A 33 P r$ was active in $C R C$ cell lines. We next constructed a conditionally replicative adenovirus named AV22EL where E1A was placed under the control of A33Pr. The tumor-specific oncolytic effect of AV22EL was investigated both in vitro and in vivo.

Results: AV22EL induced specific in vitro lysis of human CRC cell lines that expressed A33 and have negligible lytic capacity on cells that lacked or had minimal A33 expression, including normal human colonic cells. In vivo, a marked reduction of tumor growth and increased long-term survival rates were observed in nude mice xenografted with s.C. CRC tumors. Combination with 5 -fluorouracil induced an additive effect in vitro with no toxic effects in vivo. Remarkably, AV22EL completely eliminated established hepatic metastases in $>90 \%$ of mice and restored hepatic function according to biochemical parameters. Its systemic administration induced E1A expression only in the hepatic metastasis but not in normal organs.

Conclusions: These data show that AV22EL is a stringently regulated and potent oncolytic agent for the treatment of CRC.
\end{abstract}

Colorectal cancer (CRC) is the second most common cause of cancer mortality in Western countries and claimed $>50,000$ lives a year only in the United States. ${ }^{4}$ Close to $70 \%$ of patients that are affected by colorectal carcinoma undergo surgical resection and $30 \%$ to $40 \%$ of them develop a recurrent disease (1). The liver is the most common site of metastatic CRC and complete resection of hepatic metastases is the only curative option; however, surgery can be done only in $20 \%$ of patients

\footnotetext{
Authors' Affiliations: ${ }^{1}$ Laboratorio de Terapia Molecular y Celular, Instituto Leloir and Instituto de Investigaciones Bioquimicas de Buenos Aires-CONICET; ${ }^{2}$ Gene Therapy Laboratory, Liver Unit, School of Medicine, Austral University, Buenos Aires, Argentina and ${ }^{3}$ Facultad de Veterinaria, Universidad de La Plata, La Plata, Argentina

Received 5/5/08; revised 12/30/08; accepted 1/20/09; published OnlineFirst $3 / 31 / 09$.

Grant support: Rene Baron Foundation, Friends of Leloir Foundation for the struggle against cancer, and Programa Bicentenario-Banco Mundial, Conicyt, Chile CTE-06.

The costs of publication of this article were defrayed in part by the payment of page charges. This article must therefore be hereby marked advertisement in accordance with 18 U.S.C. Section 1734 solely to indicate this fact.

Note: Supplementary data for this article are available at Clinical Cancer Research Online (http://clincancerres.aacrjournals.org/).

Requests for reprints: Osvaldo L. Podhajcer, Fundacion Instituto Leloir, Av. Patricias Argentinas 435, Buenos Aires 1405, Argentina. Phone: 54-11-52387500, ext. 3107; Fax: 54-11-48652246; E-mail: opodhajcer@leloir.org.ar.

(C) 2009 American Association for Cancer Research.

doi:10.1158/1078-0432.CCR-08-1161
}

at the time of diagnosis and 5-year survival rates average $25 \%$ to $40 \%$ despite adjuvant chemotherapy (2). Among patients with metastatic colorectal carcinoma receiving as first-line chemotherapy 5-fluorouracil (5-FU) and new medications, such as irinotecan, Xeloda, oxaliplatin, Erbitux, and Avastin, the median time to progression is 8 to 9 months and their mean survival is 15 to 20.5 months $(3-6)$. It seems therefore that current CRC treatments are rather ineffective on advanced disease, showing the need for more effective and specific therapeutics to significantly increase patients' survival.

Conditionally replicative oncolytic adenoviruses (CRAd) have shown promising applications in cancer gene therapy $(7,8)$. One strategy to achieve specific elimination of the tumor mass, avoiding negative undesired effects in contiguous normal tissue, is the use of tumor-selective transcriptional regulation to control the essential early E1 genes, which are required to transactivate the other adenoviral genes $(9,10)$. Several promoters have been used to drive adenoviral replication and oncolytic activity in colorectal carcinoma, including the carcinoembryonic antigen (CEA), the telomerase, and the cyclooxygenase-2 (COX-2) promoters, which might provide a broad spectrum of therapeutic efficacy. Despite the strong oncolytic efficacy of these viruses, there is still a concern about their stringent selectivity. CEA and COX-2 promoters were

\footnotetext{
${ }^{4}$ American Cancer Society. Cancer facts and figures 2008. Atlanta: American Cancer Society; 2008
} 


\section{Translational Relevance}

We provide here preclinical data about the therapeutic efficacy of a novel oncolytic adenoviral vector, AV22EL, for treatment of colorectal cancer (CRC). AV22EL replication was driven by a $\mathrm{CRC}$-specific $\mathrm{A} 33$ antigen promoter. A33 is a membrane-bound protein located in the intestinal epithelium that is overexpressed in $95 \%$ of primary and metastatic CRC but is absent in most epithelial tissues and tumor types. A specific anti-A33 antibody is already in clinical use, suggesting its clinical relevance. AV22EL induced specifically the in vitro lysis of cells of CRC origin while showing almost no lytic activity on other cancer cell lines. AV22EL exhibited no cytocidal effect on normal human colonic cells and hepatocytes, whereas these cells were eliminated by wild-type adenovirus. AV22EL markedly reduced the in vivo growth in nude mice of established $\mathrm{CRC}$ and showed an additive effect in vitro when combined with 5-fluorouracil with no evidence of further toxic effects in vivo. Its systemic administration induced the disappearance of hepatic metastatic nodules in $>90 \%$ of mice and restored normal levels of hepatic enzymes following metastases disappearance, exhibiting no evidence of viral activity in normal organs, including normal intestine, as assessed by E1A and luciferase expression. Thus, AV22EL fulfills the criteria to become a useful and strongly specific tool for treatment of patients with CRC.

shown to be active in CEA-negative and COX-2 - negative cells, respectively $(11-13)$, the telomerase promoter could be active in $\mathrm{CD} 34^{+}$and other progenitors cells (14), whereas the use of an oncolytic virus based on the COX-2 promoter could be hampered by the rise of COX-2 expression in transient or chronic inflammation (15). An oncolytic virus was also designed based on a wnt-responding element because this pathway is strongly up-regulated in $\mathrm{CRC}$; however, the wnt pathway is also active in normal stem cells in skin, the hematopoietic system, and in intestine, as well as in neurons in several brain regions (16), although adenovirus hardly infects keratinocytes and hematopoietic cells, diminishing the risks for undesirable collateral effects $(17,18)$. However, the possibility of generating an oncolytic virus based on stringent, cancer type-specific promoter might have the advantage of its strong attenuation in normal organs, increasing the effectiveness for systemic treatment of disseminated disease.

The A33 antigen is a cell surface glycoprotein present only in the small intestine and colonic epithelium with homology to proteins of the immunoglobulin superfamily, such as the coxsackievirus and adenovirus receptor (19). In human cancer, A33 was found in 95\% of primary and metastatic colorectal carcinomas, $63 \%$ of diffuse gastric cancers, $83 \%$ of intestinaltype gastric cancers, $50 \%$ of pancreatic cancers, and $\sim 50 \%$ of the diffuse-type and mucinous cancers; it was absent in epithelial cancers, sarcomas, neuroectodermal tumors, and lymphoid neoplasms $(20,21)$. A33 is the first example of a constitutively expressed, organ-specific epithelial membrane antigen present in patients with gastrointestinal cancer (20). A33 seems to be expressed by normal replicating colonocytes located at the base of the crypt that in principle should not be accessible to an oncolytic virus (20). This restricted tissue localization and specific expression of A33 in gastrointestinal cancer led to the initiation of clinical trials in CRC aiming to target A33 by using specific antibody immunotherapy $(22-26)$.

Initial data obtained from clinical studies using oncolytic viruses have been encouraging in terms of efficacy with minimal, if any, toxicity (27). However, their efficacy in the treatment of systemic metastasis remains a major challenge. We hypothesized that the $\mathrm{A} 33$ promoter ( $\mathrm{A} 33 \mathrm{Pr}$ ) might be useful in the design of a CRAd. Thus, we constructed a new CRAd (AV22EL) in which E1A was placed under the control of A33Pr. We evaluated cell selectivity and cytotoxicity in a variety of normal and human cancer cell lines in vitro and determined the antitumor activity of the oncolytic vector on established s.c. tumors and liver metastasis following xenotransplantation of human CRC cells in nude mice. The whole data show that AV22EL is a potent oncolytic virus that can be combined with current chemotherapeutic agents.

\section{Materials and Methods}

\section{Cell lines}

The human CRC (LoVo, T84, and HT29), breast cancer (T47D), hepatocellular carcinoma (Hep-3B2), and fetal lung fibroblast (WI-38 and HFL-1) cell lines and cell lines derived from normal colon epithelia (FHC and CCD841) and human embryonic kidney cells (HEK 293) were obtained from the American Type Culture Collection. The human melanoma cell lines A375N and SB2 were kindly provided by Dr. Estela Medrano (Huffington Center on Aging, Houston, TX), and bovine aortic endothelial cells were kindly provided by Helene Sage (University of Washington, Seattle, WA). All the cell lines were grown in the recommended medium supplemented with $10 \%$ fetal bovine serum (Invitrogen Corp.), $2 \mathrm{mmol} / \mathrm{L}$ glutamine, 100 units $/ \mathrm{mL}$ penicillin, and $100 \mu \mathrm{g} / \mathrm{mL}$ streptomycin and maintained in a $37^{\circ} \mathrm{C}$ atmosphere containing $5 \% \mathrm{CO}_{2}$.

\section{Assessment of A33 mRNA expression}

Total RNA was extracted using Tri Reagent (Sigma-Aldrich Co.). RNA $(5 \mu \mathrm{g})$ was reverse transcribed with 200 units of SuperScript II Reverse Transcriptase (Invitrogen) using $500 \mathrm{ng}$ of oligo(dT) primers. cDNAs were subjected to semiquantitative PCR. Each 25 رl. reaction volume contained 1 unit Taq DNA polymerase (Invitrogen), $1 \times$ PCR reaction buffer $[20 \mathrm{mmol} / \mathrm{L}$ Tris-HCl (pH 8.4), $50 \mathrm{mmol} / \mathrm{L} \mathrm{KCl}], 1.5 \mathrm{mmol} / \mathrm{L}$ $\mathrm{Mg}_{2} \mathrm{Cl}, 200 \mu \mathrm{mol} / \mathrm{L}$ of deoxynucleotide triphosphates, and $0.4 \mu \mathrm{mol} / \mathrm{L}$ of each specific primer. For the list of primers, see Supplementary Table S1. PCR conditions were set as follows: $90 \mathrm{~s}$ at $94^{\circ} \mathrm{C}$ and then 30 cycles of $30 \mathrm{~s}$ at $94^{\circ} \mathrm{C}, 30 \mathrm{~s}$ at $60^{\circ} \mathrm{C}$, and $30 \mathrm{~s}$ at $72^{\circ} \mathrm{C}$. All the reactions were done in triplicates, and the results obtained for $\mathrm{A} 33$ were normalized to glyceraldehyde-3-phosphate dehydrogenase.

\section{Construction of AV22EL and other recombinant adenoviruses}

A 412-bp fragment of the human A33 promoter region (-105 to +307 bp relative to the transcription start site) was amplified from human lymphocyte genomic DNA using specific primers (Supplementary Table S1). The PCR product was cloned in PGEM-T easy vector (Promega Corp.) followed by subcloning in the BglII/XhoI sites of the promoterless firefly luciferase gene reporter vector pGL3-Basic (Promega) to obtain pGL3-A33.

We replaced the Rous sarcoma virus promoter of the shuttle vector pADPSY (28) with a multiple cloning site (Spe I, BclI, Kpn I, Nhe I, Mlu I, BglII, Eco RV, ClaI, SnaBI, and SalI) to create pAd-Xp. Next, a 234-bp fragment corresponding to the stop codon region of the growth hormone gene (29) was PCR cloned in the $S p e \mathrm{I} / \mathrm{Kpn} \mathrm{I}$ sites downstream of the inverted terminal repeat to create a new shuttle vector named pAd-I-Xp (see Supplementary Table S1 for the list of primers). A 
$+560 /+1,632$-bp fragment of E1A genomic sequence was PCR cloned from 293 cells, subcloned in TOPO-pCR4, and sequenced (see Supplementary Table S1). After subcloning in pcDNA3, HeLa cells were transfected to express E1A that was identified using a specific anti-E1A antibody (M73; Santa Cruz Biotechnology). A BglII/BamHI E1A fragment was subcloned into the BglII site of pAd-I-Xp followed by cloning of A33Pr upstream of E1A in MluI/BglII sites to obtain the shuttle plasmid pAd-I-A33-E1A. The identity of the final construct was confirmed by sequencing. To construct AV22EL, the cotransfection method in 293 cells was used (30). Adenovirus amplification and purification were done as described (31). Physical particle concentration [viral particles ( $(\mathrm{vp}) / \mathrm{mL}$ ] was determined by $A_{260}$ reading and biological particle concentration [determination of $50 \%$ tissue culture infective dose $\left.\left(\mathrm{TCID}_{50}\right)\right]$ was determined by standard plaque assay on 293 cells (31).

Obtention of pAd-SV40-luc, pAd-CMV-Renilla, and pAd-AV-Luc vectors is described in Supplementary Data. Viral stocks were obtained after cotransfection in HEK 293 cells as above.

\section{Luciferase assays}

Luciferase assay using plasmids. Cells seeded in 24-well plates $\left(4 \times 10^{4}\right.$ per well) were cotransfected with $0.8 \mu \mathrm{g}$ of plasmid expressing luciferase as a reporter gene and $0.1 \mu \mathrm{g}$ of pRL-CMV (Promega) using Lipofectamine 2000 (Invitrogen). Cells were harvested $46 \mathrm{~h}$ later and the dual luciferase assay was done following the manufacturer's recommendations (Promega). Luciferase activity was measured using a GENios luminometer (TECAN). Data are expressed as fold induction over pGL3Basic vector and obtained from at least three independent experiments.

In vitro luciferase assay using adenovirus. Cells seeded in 24-well plates $\left(4 \times 10^{4}\right.$ per well) were transduced with AV-Luc [multiplicity of infection (MOI), 100 land Ad-CMV Renilla (MOI, 10) in $200 \mu \mathrm{L}$ of DMEM/F 12 containing $2 \%$ fetal bovine serum. Fresh medium containing serum $(800 \mu \mathrm{L})$ was added $2 \mathrm{~h}$ later followed by cell harvesting after $48 \mathrm{~h}$. Quantification of luciferase activity followed the manufacturer's recommendations (Promega). Luciferase activity was measured using a GENios luminometer. The luciferase activity was normalized by Ad-CMV Renilla activity.

In vivo luciferase assay using adenovirus. LoVo cells $\left(5 \times 10^{6}\right)$ were injected s.c. and allowed to form tumors in the flank of 5- to 6-wk-old athymic N:NIH (S)-nu mice. When the average tumor volume reached $100 \mathrm{~mm}^{3}$, mice received $1 \times 10^{10} \mathrm{vp} /$ mouse of AV-Luc administered through the tail vein. Forty-eight hours later, luciferase activity in various tissues and in the liver metastatic nodules was determined. Quantification of luciferase activity followed the manufacturer's recommendations (Promega). Luciferase activity was measured using a GENios luminometer. The luciferase activity was normalized by milligram of protein Ad.

\section{$\beta$-Galactosidase staining assay}

Cell infectivity was assessed using an adenovirus expressing the bacterial $\beta$-galactosidase protein (Ad-Bgal). Twenty-four hours after plating, cells were infected with Ad-Bgal at different MOI in serum-free medium for $42 \mathrm{~h}$, and the cells were incubated for an additional $72 \mathrm{~h}$ in DMEM/F12 containing 10\% fetal bovine serum. Infected cells were washed with PBS, fixed, and evaluated for $\beta$-galactosidase activity by incubation in 5-bromo-4-chloro-3-indolyl- $\beta$-D-galactopyranoside (X-Gal) staining solution (32).

\section{Assessment of E1A levels}

For determination of E1A mRNA levels, $1.5 \times 10^{5}$ cells per well were seeded in a six-well plate. The next day, cells were infected with the indicated viruses at 1,000 MOI or mock infected. After 24,48 , and $72 \mathrm{~h}$, cells were lysed and total RNA was obtained. A semiquantitative PCR for E1A was done using the set of primers described in Supplementary Table S1.

\section{Western blot}

LoVo cells were transduced with AV22EL or Ad-WT (kindly provided by Dr. Andre Lieber, Seattle, WA) at various MOIs. After $72 \mathrm{~h}$, total protein extracts were prepared in lysis buffer $[10 \mathrm{mmol} / \mathrm{L}$ Tris ( $\mathrm{pH} 7.5)$, $1 \mathrm{mmol} / \mathrm{L}$ EDTA, $150 \mathrm{mmol} / \mathrm{L} \mathrm{NaCl}, 1 \%$ Triton X-100 (Sigma), $0.5 \%$ deoxycholic acid (Sigma), 0.1\% SDS with a protease inhibitor cocktail] Total protein extracts were separated in 10\% SDS-PAGE and transferred to nitrocellulose membranes (Bio-Rad Laboratories). The membranes were probed with anti-E1A antibody (M73; Santa Cruz Biotech) and anti- $\beta$-actin antibody (A4700; Sigma) was used as a loading control. Enhanced chemiluminescence reagents were used to detect the signals following the manufacturer's instructions (Amersham).

\section{Cytopathic effect}

Cells were seeded in 24-well plates at a density of $1 \times 10^{4}$ per well. The next day, cells were infected with AV22EL or Ad-WT adenovirus at a MOI ranging from 1 to 1,000 . The cytopathic effect was monitored by staining viable cells with crystal violet $10 \mathrm{~d}$ after infection (31). Density of gel bands was analyzed by using the Imagel program developed by Wayne Rasband (NIH, Bethesda, MD).

T84-EGFP cells correspond to a single-cell clone obtained by limiting dilution after cell transfection with a plasmid expressing EGFP and selection in G418 $(750 \mu \mathrm{g} / \mathrm{mL})$. WI-38 and T84 EGFP cells were seeded in 24 -well plates at a density of $5 \times 10^{4}$ per well, each. The next day, cells were infected with AV22EL or Ad-WT at MOI of 500. Cells were photographed at day 7 after the initiation of the experiment under light and UV microscope. At the end of the experiments, cells were counted in a Neubauer chamber under light and UV microscope. The experiments were done thrice.

\section{Hepatocyte isolation}

Liver samples were collected from one patient undergoing partial hepatectomy. Sample collection was obtained under informed consent with the approval of the ethics committee of the Hospital University Austral. Hepatocyte isolation was done under sterile conditions using a modified two-step collagenase perfusion technique (33). Liver samples were homogenized with $0.1 \%$ collagenase for $30 \mathrm{~min}$, twice. Cell suspension was centrifuged at $50 \times \mathrm{g}$ for $5 \mathrm{~min}$ at $4^{\circ} \mathrm{C}$. The cells were purified by density gradient centrifugation $\left(1,278 \times g, 20\right.$ min, $\left.4^{\circ} \mathrm{C}\right)$ using a $25 \%$ Percoll solution (density of $1.124 \mathrm{~g} / \mathrm{mL}$ ) in cold PBS. After isolation, hepatic cells were counted and viability was assessed by trypan blue exclusion test. Cells were seeded in collagen type I. At day 5 , glycogen storage was detected by procedure periodic acid-Schiff.

\section{In vitro assays combining AV22EL with 5-FU}

Cells seeded in 96-well plates $\left(2 \times 10^{3}\right.$ per well) were infected the next day with AV22EL or treated with 5-FU (Microsules Bernabo). In one experimental condition, cells were first treated with 5 -FU for $24 \mathrm{~h}$, the medium was then removed, and the cells were transduced with AV22EL. In another experimental condition, cells were first infected with AV22EL for $24 \mathrm{~h}$ and then the medium was replaced with fresh medium containing 5-FU. Five days after treatment, cell viability was established with the 3-(4,5-dimethylthiazol-2-yl)-2,5-diphenyltetrazolium bromide (MTT) assay and the absorbance was read at $570 \mathrm{~nm}$ using a Bio-Rad Model 550 microplate reader (Bio-Rad Laboratories) All assays were carried out in six different replicates.

\section{Multicellular spheroids}

The semisolid liquid overlay culture technique was used to produce multicellular spheroid cultures (34). Briefly, $1 \times 10^{4}$ cells were seeded onto a semisolid $1 \%(\mathrm{w} / \mathrm{v})$ agarose per well layer in 96-well plates in $200 \mu \mathrm{L}$ of medium. Seventy-two-hour-old spheroids were infected at MOIs of 10,100, and 500 for $7 \mathrm{~d}$ with the different adenoviruses. At the end of the experiment, spheroids were photographed and growth was quantified by regular measurement of cross-sectional area of individual spheroids.

\section{Virus yield}

Six-well plates were seeded with $1 \times 10^{5}$ cells per well $24 \mathrm{~h}$ before infection. Cells were infected at a MOI of 50 for $2 \mathrm{~h}$ in serum-free 
medium. Then, the virus-containing media were removed, monolayers were washed twice with PBS, and $1 \mathrm{~mL}$ of complete medium was added to each well. At $72 \mathrm{~h}$ after infection, the cells were scraped into culture medium and lysed by three cycles of freezing and thawing. The supernatant was tested for the viral titer by an end point cytocidal assay as described by Li et al. (35).

\section{In vivo studies on s.c. tumors and hepatic metastases}

Five- to 6-wk-old female and male athymic N:NIH (S)-nu mice (obtained from the animal facility of the Faculty of Veterinary, University of La Plata) were s.c. injected in one flank with $5 \times 10^{6}$ cells. When the average tumor volume reached $100 \mathrm{~mm}^{3}$, mice received $1 \times 10^{10} \mathrm{vp} /$ mouse of AV22EL or vehicle administered intratumorally on days 1, 4, and 7. For in vivo assays combining AV22EL with 5-FU, mice were injected with AV22EL followed by i.p. administration of 5-FU (30 $\mathrm{mg} / \mathrm{kg}$ for $5 \mathrm{~d}$ ) starting $1 \mathrm{~d}$ after the last AV22EL injection. Tumor volumes were estimated twice a week from caliper measurements [volume $=0.52 \times(\text { width })^{2} \times$ length]. In vivo experiments were done following institution guidelines approved by the NIH, and all animals under study received food and water ad libitum. For colorectal liver metastases studies, LoVo cells $\left(1 \times 10^{6}\right)$ were injected via the portal vein of female and male nude mice. At day 7 after cell inoculation, when multiple tiny spots of tumor metastases were confirmed in parallel experimental groups, mice received tail vein injections of AV22EL, Ad-Bgal, or vehicle. Administration was repeated 48 and $72 \mathrm{~h}$ later. Animals were bled and serum was used to determine albumin, aspartate aminotransferase, and alkaline phosphatase levels.

For assessment of E1A expression in vivo, mice, harboring or not established liver metastases, were injected once via the tail vein with AV22EL or PBS. Three days later, mice were sacrificed and organs were removed for obtention of total RNA.

For in vivo detection of viral replication, hepatic metastases were fixed in $4 \%$ paraformaldehyde for $1 \mathrm{~h}$, cryopreserved overnight in $30 \%$ sucrose, embedded in tissue OCT, and stored at $-20^{\circ} \mathrm{C}$. Cryostat sections $(9 \mu \mathrm{m})$ were mounted on gelatin-coated slides and incubated with goat anti-adenoviral hexon protein antibody AB1056 (Chemicon International). Biotinylated secondary antibodies were used in conjunction with the Vectastain avidin-biotin complex method kit (Vector Laboratories), and finally, the reaction was visualized by using 3,3'-diaminobenzidine chromogen (Dako). Slides were counterstained with hematoxylin and photographed on an Olympus BX60 microscope. The liver metastasis was sectioned in three pieces, each $\sim 0.5 \mathrm{~mm}$ in width. Histologic analysis was done on one $5-\mu \mathrm{m}$ tissue section of each piece.

\section{Assessment of intratumor viral replication}

LoVo cells $\left(5 \times 10^{6}\right)$ were injected s.c. and allowed to form tumors in the flank of 5- to 6-wk-old athymic N:NIH (S)-nu mice. When the average tumor volume reached $100 \mathrm{~mm}^{3}$, mice received $1 \times 10^{10}$ $\mathrm{vp} /$ mouse of AV-Luc or AV22EL administered intratumorally on day 1. Seven days after injection, total DNA was obtained from tumors (Illustra tissue \& cells genomicPrep Mini Spin, GE Healthcare) and E4 gene was measured by quantitative real-time PCR $(36,37)$. Genomic DNA was subjected to real-time PCR in an iCycler iQ System (Bio-Rad Laboratories). Each $25 \mu \mathrm{L}$ reaction volume contained 1 unit Platinum Taq DNA polymerase (Invitrogen) $1 \times$ PCR reaction buffer $[20 \mathrm{mmol} / \mathrm{L}$ Tris- $\mathrm{HCl}(\mathrm{pH} \mathrm{8.4}), 50 \mathrm{mmol} / \mathrm{L} \mathrm{KCl}, 1.5 \mathrm{mmol} / \mathrm{L} \mathrm{Mg} 2 \mathrm{Cl}, 2.5 \mathrm{~g}$ bovine serum albumin, $0.01 \%$ glycerol, $0.4 \mu \mathrm{mol} / \mathrm{L}$ of each specific primer targeting the E4 region (Ad5, nucleotides 33806-34074; Supplementary Table S1), $200 \mu \mathrm{mol} / \mathrm{L}$ of deoxynucleotide triphosphates, and $0.3 \times$ SYBR Green Solution. PCR conditions were set as follows: $150 \mathrm{~s}$ at $94^{\circ} \mathrm{C}$ and then 39 cycles of $45 \mathrm{~s}$ at $94^{\circ} \mathrm{C}, 30 \mathrm{~s}$ at $60^{\circ} \mathrm{C}$, and $30 \mathrm{~s}$ at $72^{\circ} \mathrm{C}$. All the reactions were done in triplicate. Analysis of data was carried out using the iCycler software (Bio-Rad Laboratories) by comparing test sample with a standard. Standard curves were generated by serial dilutions of $10^{10}$ copies of adenoviral DNA in a solution of control cellular genomic DNA.

\section{Statistical analysis}

Statistical analyses of luciferase studies, spheroids, and in vivo experiments were determined by ANOVA followed by Tukey's test. Statistical analyses of 5-FU curves and viral replication in vivo were determined by ANOVA (two-way ANOVA) followed by Bonferroni's test. A $P$ value of $<0.05$ was considered significant. Statistical analyses of serum liver chemistries were done by the Dunnett's multiple comparison test. Survival was determined by the method of KaplanMeier. Log-rank test was used to compare differences in survival. Data analysis was done with the GraphPad Prism (GraphPad Software, Inc.).

\section{Results}

Analysis of A33 mRNA expression and A33 promoter activity in different human cell lines. To establish whether A33 gene promoter could be useful for the construction of a CRAd, we first evaluated A33 mRNA expression levels in different malignant and notmal human cells by semiquantitative PCR. Only colorectal carcinoma cell lines LoVo, T84, and HT29 showed A33 mRNA expression, whereas normal colonic cells CCD841 showed approximately one tenth the levels of A33 mRNA observed in LoVo cells (Fig. 1A). A33 mRNA was not expressed in additional malignant cells, normal fibroblasts, and endothelial cells (Fig. 1A). A33Pr, cloned in the promoterless plasmid pGL3 basic, was essentially active only in human CRC cells LoVo, T84, and HT29, whereas human mammary and melanoma cells showed strongly reduced activity (Supplementary Fig. S1A). In coincidence, an adenoviral vector expressing the luciferase gene driven by $\mathrm{A} 33 \mathrm{Pr}$ (AV-Luc) was highly active only in CRC cells; among A33-nonexpressing cells, AV22EL showed a slight activity in SB2 melanoma cells (Fig. 1B and see below)

We next constructed a CRAd (AV22EL) where E1A was placed under the control of A33Pr (Supplementary Fig. S1B). AV22EL genome lacks the adenoviral E3 region and contains the IA33Pr-E1A cassette introduced in the E1 region of the viral backbone. E1A expression driven by A33Pr was confirmed by Western analysis after transduction of LoVo cells at different MOIs of AV22EL (Fig. 1C)

Selective replication and lytic activity of AV22EL in CRC cells. AV22EL showed marked in vitro cytocidal effect against LoVo and T84 human CRC cells expressing the highest A33 mRNA levels (Fig. 2A and B). AV22EL was at least 2 orders of magnitude less effective on HT29 human colorectal carcinoma cells that expressed the lowest A33 mRNA level among the CRC cells (Fig. 2A and B). Interestingly, the presence of the $\mathrm{E} 3$ region was slightly detrimental for the in vitro lytic activity of the A33Pr-based CRAd (Supplementary Fig. S2A). AV22EL was only effective at 1,000 MOI on human Hep-3B hepatoma and SB2 melanoma cells, whereas it had essentially no cytocidal effect on human A375 melanoma cells, T47D breast cancer cells, WI-38 and HFL-1 fibroblasts, and bovine aortic endothelial cells (Fig. 2A and B). Ad-WT was active in CRC cells at a lower MOI than AV22EL (Fig. 2A and B; Supplementary Fig. S2B); however, its lytic activity was independent of the A33 levels expressed by the different cell types (Fig. 2A and B).

AV22EL specificity was further confirmed when T84 CRC cells expressing EGFP were mixed in vitro with WI-38 fibroblasts. Under these conditions, only T84-EGFP cells were lysed by AV22EL, whereas neighbor WI-38 fibroblasts were not affected (Supplementary Fig. S2C and D). On the other hand, 
A

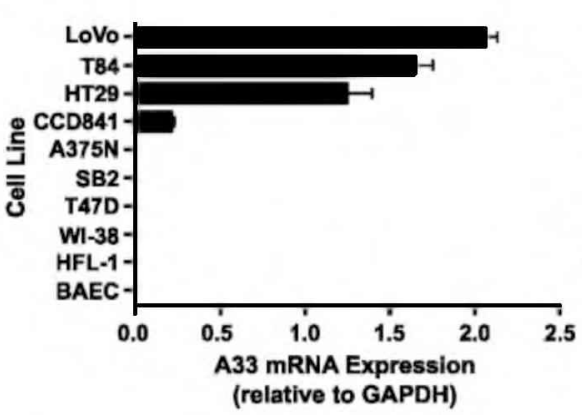

B

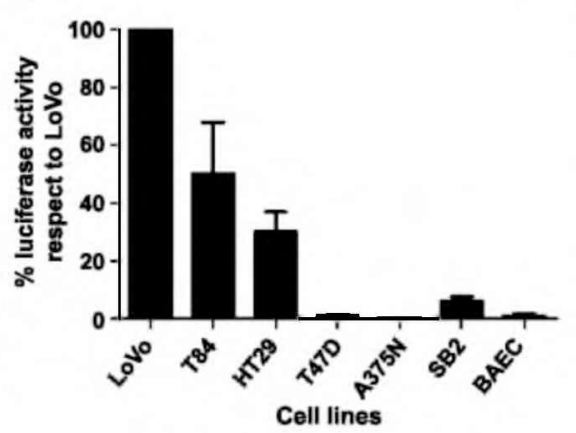

C

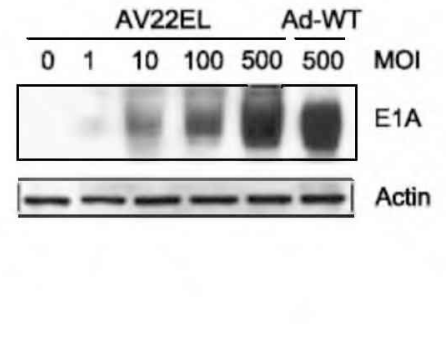

Fig. 1. Characterization of A33 promoter activity in different cell types. A. A33 mRNA levels in different cell types. A33 mRNA levels were assessed as described in Materials and Methods. All the experiments were done in triplicate, and the data were normalized to glyceraldehyde-3-phosphate dehydrogenase (GAPDH) mRNA levels. Columns, mean; bars, SD. B, activity of the A33 promoter. Cells were transduced with $5 \times 10^{6} \mathrm{vp} / \mathrm{mL}$ of AV-Luc and Ad-CMV Renil/a as described in Materials and Methods. Ce extracts were assayed $2 \mathrm{~d}$ later for firefly and Renilla luciferase. Columns, mean of three independent experiments; bars, SD. $C$, Western blot analysis showing E1A expression in LoVo cells infected with AV22EL.

Ad-WT efficiently lysed both cell types (Supplementary Fig. S2D)

As an alternative way to establish the selectivity of AV22EL, cells were infected with AV22EL or Ad-WT and the viral yield was measured by plaque assay at 72 hours after infection. AV22EL replicated very efficiently in LoVo and T84 colon cancer cells, although at a lower level than Ad-WT (Fig. 2C). On the other hand, AV22EL replicated inefficiently in A33nonexpressing melanoma and breast cancer cell lines that produced $10^{5}$ - to $10^{6}$-fold less progeny than A33-positive cells. The virus did not replicate at all in normal colon cells, fibroblasts, and endothelial cells (Fig. 2C). Interestingly, HT29 colon cancer cells that express A33 showed viral yield levels similar to those observed in SB2 melanoma cells that did not express A33 (Fig. 2C). Despite that, AV22EL showed 10-fold higher lytic capacity on HT29 cells compared with SB2. By using a replication-defective adenovirus expressing the $\beta$-galactosidase gene followed by X-Gal staining, we observed that at the largest MOI of 1,000, only $40 \%$ of HT2 2 cells were transduced compared with $\sim 100 \%$ of SB2 melanoma cells (Supplementary Fig. S2E). On the other hand, HT29 CRC cells infected with 1,000 MOI of AV22EL exhibited clearly detectable levels of E1A, whereas only faint levels of E1A were seen in SB2 melanoma cells under the same conditions (Supplementary Fig. S2F). Ad-WT infection led to similar E1A expression levels in both HT29 and SB2 cells (Supplementary Fig. S2F). These data show that AV22EL replicates in HT29 cells at a better extent compared with SB2 melanoma cells, although, based on E1A expression, it seems that SB2 melanoma cells can support a certain level of AV22EL replication.

Complete attenuation of AV22EL lytic capacity on normal human colonic cells and hepatocytes. To further establish that AV22EL activity was attenuated in normal cells, we assessed its cytocidal effect on CCD841 and FHC cells derived from normal colon epithelia. Ad-WT efficiently lysed both LoVo colorectal carcinoma cells and normal colonic epithelial cells at a MOI of 100 (Fig. 3A). However, AV22EL exerted a cytocidal effect on LoVo cells but had no lytic effect on CCD841 and FHC cells, suggesting that AV22EL is strongly attenuated in normal colonic cells (Fig. 3A). Of relevance was also the evidence that
AV22EL had no lytic activity on normal human hepatocytes at the largest MOI of 1,000, whereas Ad-WT exhibited a strong lytic effect (Fig. 3B). The inset also shows that Ad-WT, but not AV22EL, could replicate in normal hepatocytes (Fig. 3B).

AV22EL lytic capacity on cells growing in multicellular spheroids. Multicellular spheroids represent a tridimensional in vitro model of an avascular growing tumor. Three-day-old spheroids were infected in situ with AV22EL or Ad-WT at different MOIs and followed for additional 7 days. At the end of the experiment, spheroids were photographed and sized. Zero MOI corresponds to the average volume of noninfected spheroids at the end of the experiment (Fig. 4; Supplementary Table S2). Spheroids contained in average 5,000 cells at the beginning of the experiment, whereas noninfected spheroids grew up to an average of 30,000 cells/each after 7 days (Supplementary Fig. S3A). In the photography, A375N spheroid volume seems larger due to the fact that $\mathrm{A} 375 \mathrm{~N}$ cell size is larger than the others (data not shown). Ad-WT inhibited $\sim 50 \%$ the growth of spheroids made of A375N and SB2 melanoma cells, whereas AV22EL had essentially no inhibitory effect (Fig. 4A; Supplementary Table S2). On the other hand, AV22EL was as effective as Ad-WT on the growth inhibition of spheroids made of LoVo cells (Fig. 4A; Supplementary Table S2). These results confirmed the selective oncolytic capacity of AV22EL on CRC cells.

In vivo antitumor effect of AV22EL on established tumors. Nude mice were initially xenotransplanted in the flank with tumorigenic inocula of LoVo or SB2 cells. When the average tumor volume reached $100 \mathrm{~mm}^{3}$, mice received $1 \times 10^{10} \mathrm{vp} /$ mouse of AV22EL or vehicle administered via intratumor injection at days 1,4 , and 7 . AV22EL was effective in inhibiting tumor growth in $100 \%$ of mice harboring established LoVo tumors (Fig. 5A, left), including complete tumor regression in two mice that lasted for 200 days (data not shown). However, AV22EL did not affect SB2 melanoma cell growth despite an initial inhibitory effect (Fig. 5A, left) that is probably in accordance with the faint E1A levels reflecting viral replication that were observed after SB2 infection with AV22EL (Supplementary Fig. S2F). No evidence of tumor growth inhibition was observed in mice harboring 


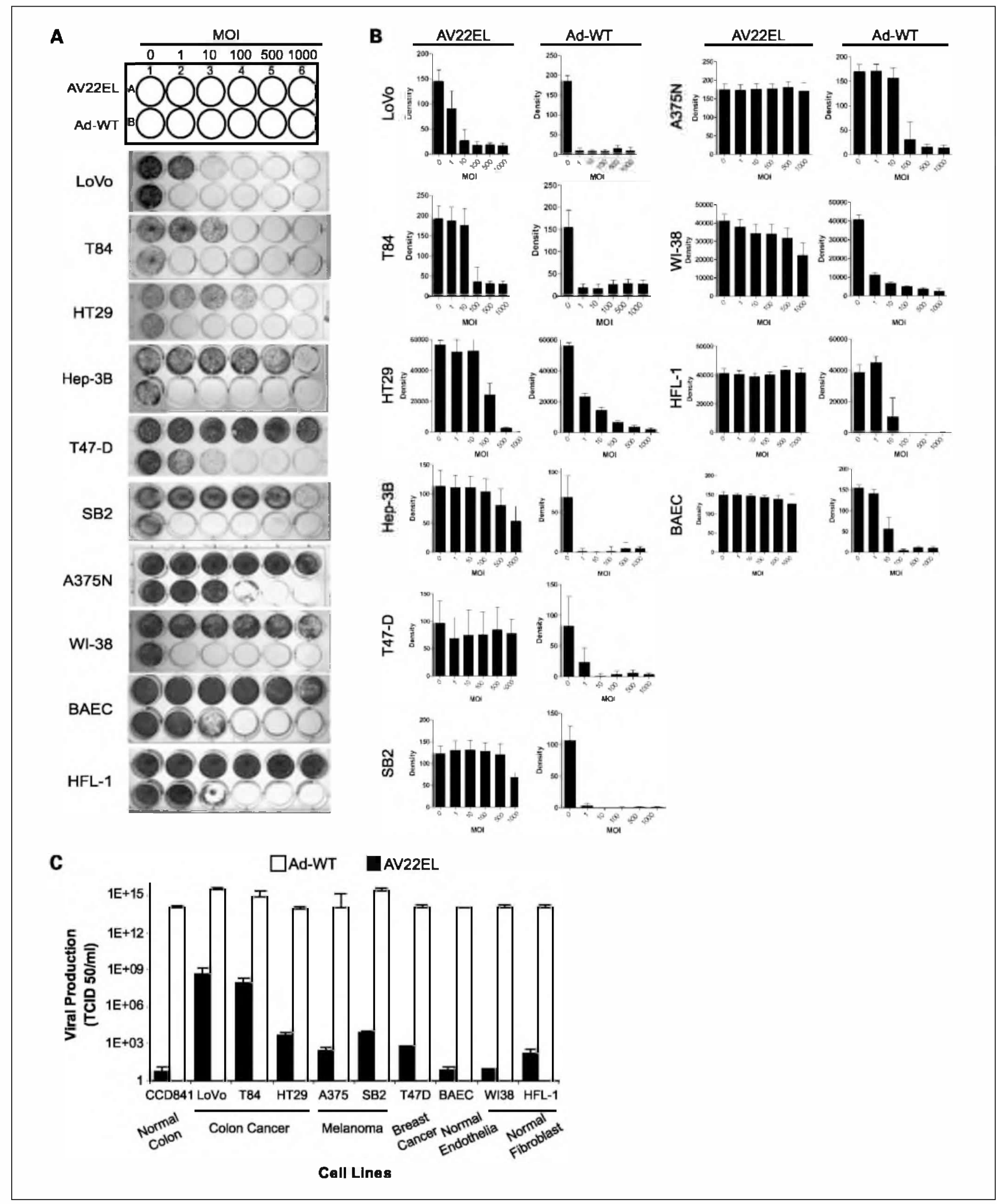

Fig. 2. AV22EL cytocidal effect and replication capacity in different cell types. A, cytocidal effect of AV22EL on different cell types. AV22EL exerted a cytacidal effect only on LoVo, T84, and HT29 colon cancer cells, whereas Ad-WT showed cytocidal effect on every cell type. Cells were cultured for $10 \mathrm{~d}$ before staining with crystal vialet. $B$, quantification of crystal violet levels was assessed as described in Materials and Methods. $C$, virus yield study of AV22EL on different normal and tumor cell lines. Columns, mean; bars, SD. 
LoVo tumors treated with PBS. Kaplan-Meier curve showed that AV22EL-treated mice survived significantly longer than control mice $(P<0.01$; Fig. 5A, right $)$. There was no sign of virus-related toxicity or weight loss associated with the treatment (data not shown). To confirm that AV22EL replicated in situ, we injected intratumorally mice harboring colon cancer tumors of $100 \mathrm{~mm}^{3}$ average volumes. Seven days later, $1.2 \times 10^{10}$ viral copies per tumor were recovered after AV22EL administration compared with $1.7 \times 10^{8}$ copies per tumor obtained after administration of a nonreplicating adenovirus expressing luciferase (AV-Luc; Fig. 5A, right).

Combination of AV22EL with 5-FU. Because s.c. tumors were not completely eliminated by AV22EL treatment, we assessed whether the combination of AV22EL with the commonly used chemotherapeutic agent 5-FU will improve therapeutic efficacy. After initial attempts to combine AV22EL and 5-FU in different ways, we observed that preincubation of cells with AV22EL followed by washing and addition of $5 \mu \mathrm{g} / \mathrm{mL}$ 5-FU for 4 additional days enhanced the lytic effect of 5-FU both on LoVo and HT29 cells, although in the latter the effect was less pronounced (Fig. 5B, a). T84 cells were highly sensitive to 5-FU alone (Fig. 5B, a). When 5-FU concentration was lowered to $0.1 \mu \mathrm{g} / \mathrm{mL}$, we observed that $10 \mathrm{MOI}$ of AV22EL significantly enhanced the lytic effect of 5-FU on the three colon cancer cell lines compared with 5-FU alone (Fig. 5B, b). AV22EL was completely attenuated in normal cells because it was unable to
Fig. 3. Lack of $A V 22 E L$ cytocidal effect on normal cells. $A$, lack of cytocidal effect of AV22EL on normal colonic cells. AV22EL exerted a cytocidal effect anly on LoVo CRC cells but had no effect on CCD841 and FHC normal colonic cells grown as monolayers. Ad-WT lysed both normal and tumor cells. Cells were photographed under phase-contrast light microscope $7 \mathrm{~d}$ after the initiation of the experiment. Insets, crystal violet staining. $B$, lack of cytocidal effect of AV22EL on human normal hepatocytes. Cells obtained as described in Materials and Methods were infected with AV22EL orAd-WT and survival was established with the MTT assay at the end of the experiments. Columns, mean of twa independent experiments with six replicates; bars, SD. *, statistically significant differences compared with the contral $(P<0.05)$. Inset, viral yield after infection of the hepatocytes with the different viruses.

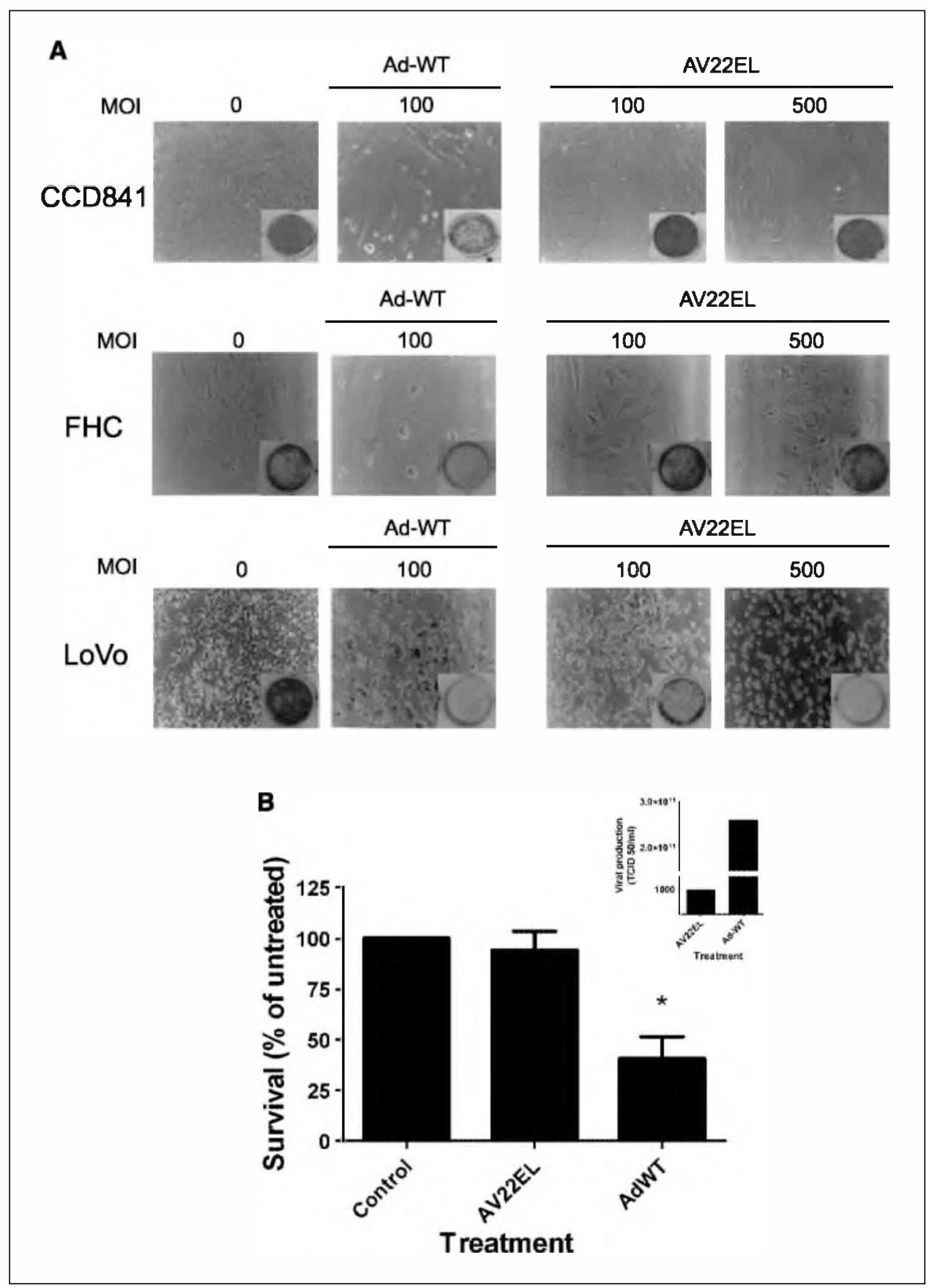




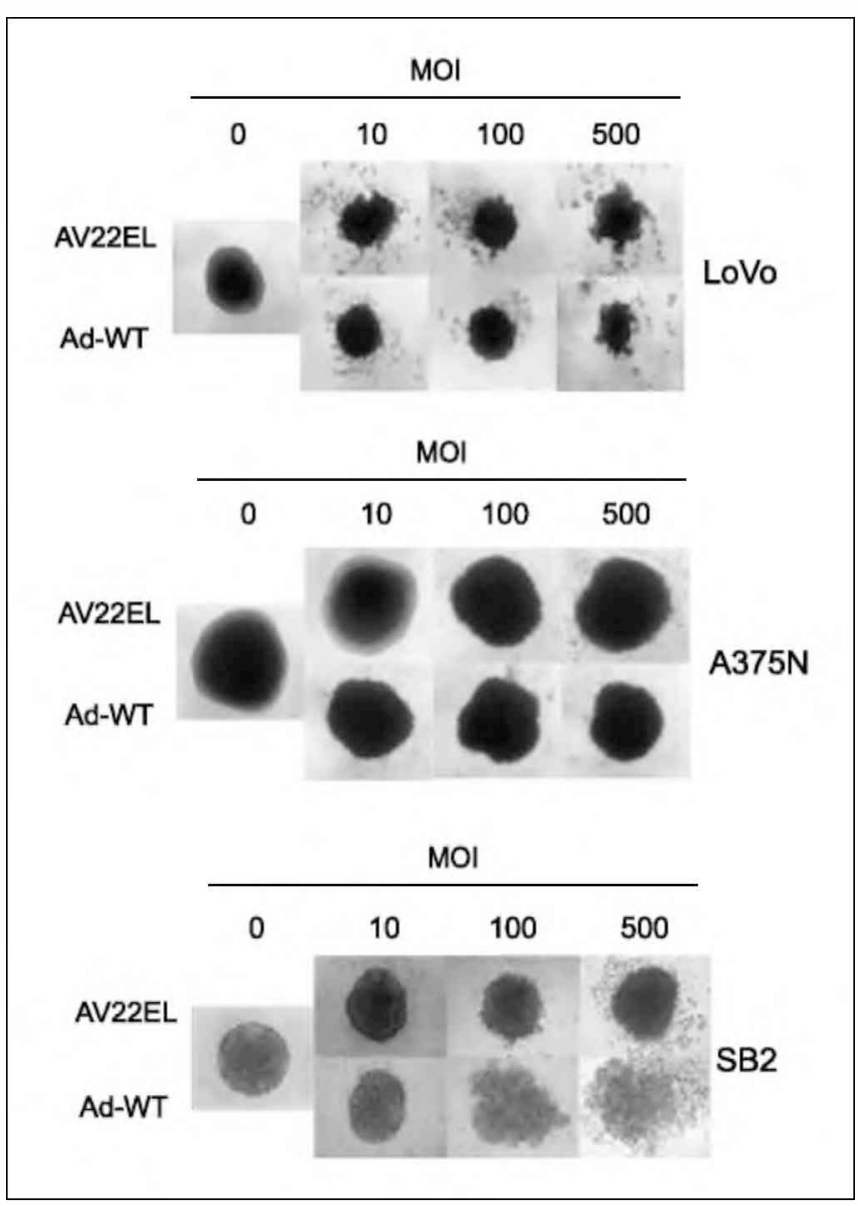

Fig. 4. AV22EL effects on spheroid growth. Spheroids prepared with $A 375 \mathrm{~N}$ and SB2 human melanoma cells and LoVo CRC cells were transduced with increasing $\mathrm{MOI}$ of AV22EL or Ad-WT. Photographs of the spheroids were taken under phase-contrast light microscopy.

enhance the growth inhibition induced by 5 -FU on normal colon cells and fibroblasts (Fig. 5B,c).

We next evaluated if this improved inhibitory effect in vitro could be extrapolated in vivo. Mice harboring s.c. LoVo tumors were treated with PBS, 5-FU alone, AV22EL alone, or the combination of AV22EL followed by 5-FU. 5-FU alone did not significantly inhibit tumor growth (Fig. 5C), whereas mice treated with AV22EL induced a strong delay in tumor growth in $100 \%$ of mice (Fig. 5C). Adding 5-FU in combination with the CRAd did not significantly improve the tumor growthinhibitory effect observed with AV22EL alone (Fig. 5C). We observed no evidence of toxicity or weight loss associated with the treatments that included the CRAd alone or combined with 5-FU (data not shown)

Liver metastases elimination following systemic AV22EL delivery. Eradication of hepatic metastases is a key factor for improved CRC prognosis (1). Therefore, we used an efficient model for metastases development in the liver by injecting nude mice in their portal vein with CRC cells. After we have confirmed that hepatic metastases developed, we assessed whether systemic administration of AV22EL might suppress growth of established tumor nodules.

Mice were treated with AV22EL, Ad- $\beta$ gal, or PBS at days 7, 10, and 14 after the initial cell injection. Seven days after the last viral administration, mice were sacrificed. Almost all the mice injected with Ad-ßgal or PBS developed multiple tumor nodules throughout the liver by day 21 after cell injection (Fig. 6A). Mice treated with PBS or Ad-Bgal showed metastatic nodules that displayed areas with glandular-like arrangement of tumor cells (Fig. 6A, left). Gross observation and histopathologic analysis of autopsies confirmed that 10 of 11 mice injected with AV22EL were free of metastatic nodules (Fig. 6A, right), whereas 1 animal showed strongly reduced metastatic areas (data not shown). None of the mice injected with PBS or Ad-Bgal showed evidence of therapeutic benefit (Fig. 6A, right). In addition, abundant expression of the adenovirus hexon protein was detected in tumor metastasis, but not in the normal liver, 72 hours after AV22EL administration (Fig. 6B). Moreover, systemic administration of AV22EL led to E1A mRNA expression only in liver metastatic nodules, whereas other organs, such as spleen, kidney, intestine, lung, and nonmetastatic liver, exhibited no E1A expression (Fig. 6C, left). Similarly, systemic administration of AV-Luc, where luciferase activity was driven by the $\mathrm{A} 33$ promoter, showed activity exclusively in liver metastatic nodules (Fig. 6C, right).

To establish whether administration of AV22EL might affect liver function, we also assessed liver enzymes as a surrogate readout of liver toxicity. Growth of metastatic nodules in mice treated with PBS or control Ad- $\beta$ gal adenovirus decreased albumin levels while inducing an increase in aspartate aminotransferase and alkaline phosphatase levels (Fig. 6D). Interestingly, albumin levels seemed normal in mice treated with AV22EL, whereas the differences in albumin levels remained statistically significant between the "no tumor" group compared with the Ad- $\beta$ gal or PBS groups of mice (Fig. 6D). Aspartate aminotransferase levels also seemed normal in the AV22EL-treated group, whereas the Ad-ßgal group also exhibited diminished levels compared with the PBS-treated group (Fig. 6D). Alkaline phosphatase differences were not statistically significant between the different groups, although alkaline phosphatase levels in the AV22EL group were similar

Fig. 5. In vitro and in vivo efficacy of AV22EL in combination or not with 5-FU. A, in vivo efficacy of AV22EL on s.c. established LoVo tumors. Left, mice carrying established LoVa $(n=12)$ or SB2 tumars $(n=6)$ were treated with AV22EL, whereas control mice $(n=8)$ received vehicle alone. AV22EL exerted a significant antitumar effect $(P<0.005$ at day 35). Middle, Kaplan-Meier curve showing increased survival in mice induced by AV22EL treatment compared with the other groups. " $P$ ( 0.01, when the AV22EL-treated group was compared with the vehicle-treated group. Right, intratumor replication of AV22EL compared with Ad-Luc. Adenovirus was injected intratumorally into LoVo tumors on day 0 at $10^{10} \mathrm{VP} /$ tumor. Viral genome content was measured by quantitative real-time PCR. ${ }^{*}, P<0.05$. $B$, a to $C$, in vitro cytocidal effect of AV22EL combined or not with 5-FU. Cells were incubated with two different cancentrations of 5-FU or with AV22EL alone or in sequential combination. In the latter case, cells were transduced with AV22EL at the indicated MOls for 24 h and washed and then 5 -FU was added for 4 additional days. Columns, mean; bars, SD. The asterisks indicate statistically significant differences compared with cells treated with 5 -FU alone: *, $P<0.05 ;{ }^{* *}, P<0.01 ;{ }^{* * *}, P<0.001$. C, in vivo efficacy of AV22EL combined ar not with 5-FU on s.c. established LoVo tumors. Left, mice carrying established LoVo tumors were treated with AV22EL alone $(n=6)$, 5-FU alane ( $n=4)$, and AV22EL/5-FU in combination $(n=6)$. Control mice $(n=4)$ were treated with vehicle alone. AV22EL combined ar not with 5 -FU showed a statistically significant antitumar effect $(P<0.005$ at day 45). Right, Kaplan-Meier survival curve showing the increased survival induced by AV22EL treatment combined or not with 5 -FU compared with the vehicle-treated group. ${ }^{*}, P<0.01$. 


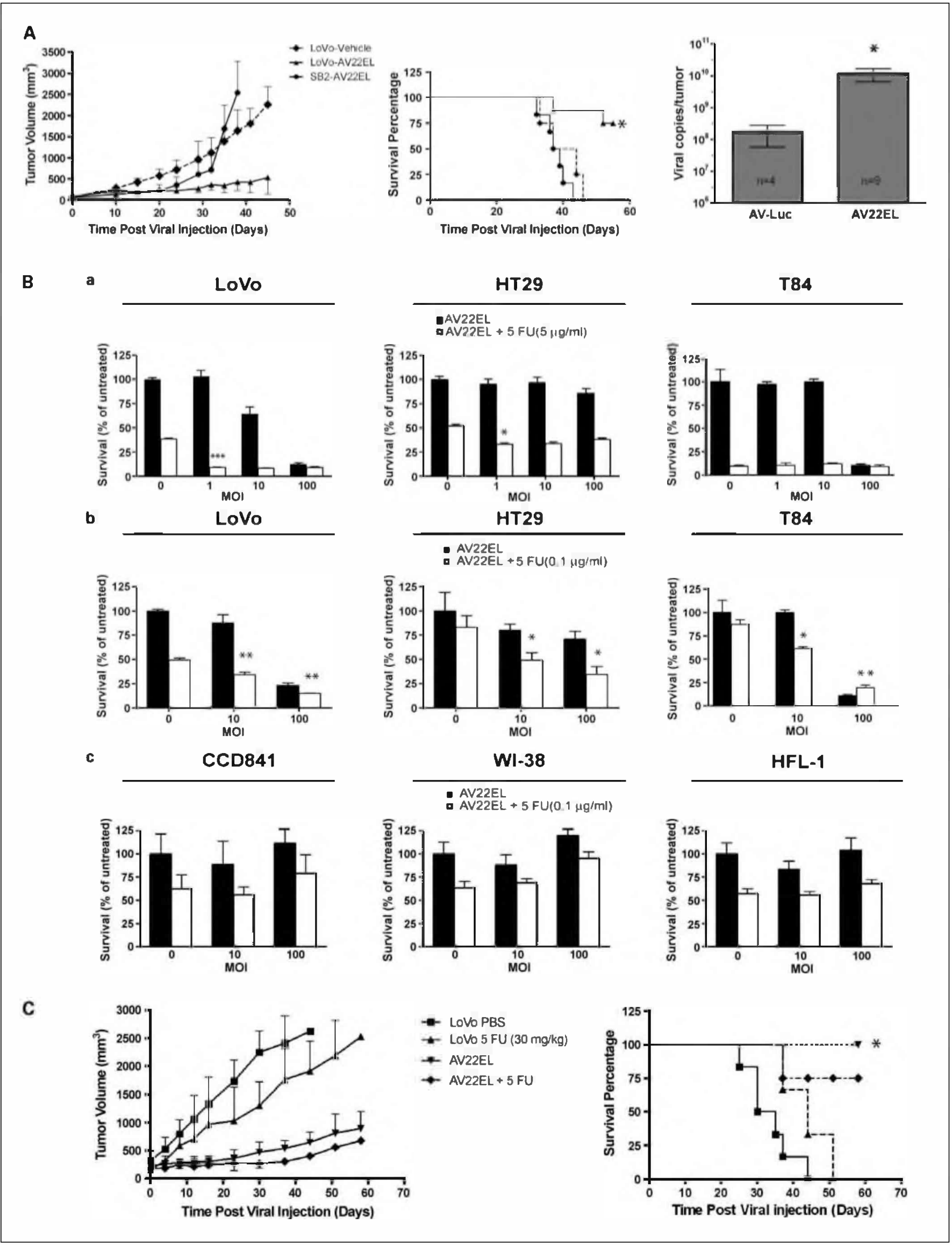


to those observed in the no tumor group (Fig. 6D). These data suggest that AV22EL not only was therapeutically efficient to inhibit metastatic growth but also was able to restore the normal function of the liver.

\section{Discussion}

Here, we show that a conditionally replicative oncolytic adenovirus based on the A33 promoter was able to inhibit the in vivo growth in nude mice of established colorectal carcinoma and eliminated established hepatic metastases. AV22EL was highly selective because it was completely ineffective on cells that did not express A33.

Most of the oncolytic viruses are developed based on promoters that can be active in more than a single cancer type to allow for a wider use without the therapeutic limitation of using the oncolytic virus in only one cancer type. This is the case for the CEA, COX-2, T-cell factor, and telomerase promoters that have been mentioned in Introduction. An additional CRAd based on a double heterologous promoter Ki67 and COX-2 showed significant oncolytic activity on s.c. established colorectal tumors, although its effectiveness on established hepatic metastases was not assessed (38). More recently, a CRAd expressing E1A driven by the nonspecific Rous sarcoma virus promoter and the proapoptotic protein tumor necrosis factor-related apoptosis-inducing ligand was effective in inducing the elimination of established metastases obtained from colon carcinoma cells (39). The concern is that these promoters are active in different types of normal cells or under mild pathologic conditions, such as inflammation, limiting their systemic use due to their potential toxicity to normal organs.

Instead, oncolytic viruses such as AV22EL that are based on stringent, cancer type-specific promoters have the potential advantage of their strong attenuation in normal organs, increasing their effectiveness for systemic treatment of disseminated disease. AV22EL has been cytocidal in vitro on colorectal carcinoma cells expressing A33 antigen growing in monolayers and as spheroids, indicating that AV22EL was able to penetrate the cell-cell adhesive interactions established in spheroid systems. On the other hand, AV22EL was rather ineffective on cells that did not express A33, such as melanoma and normal colorectal cells, which expressed very low levels of A33. Although this novel CRAd exhibited a slight lytic activity on hepatoma cells and certain human melanoma cells at the highest MOI, normal hepatocytes were completely refractory to AV22EL while they were lysed by the wild-type (WT) adenovirus.

The present data indicate that AV22EL exhibited several orders lower viral yield than WT adenovirus. In preliminary studies, we compared AV22EL with an adenoviral construct prepared with the JM17 backbone that includes the E3 region (40). Side by side comparison of the two CRAds showed that the presence of the entire E3 region was detrimental to CRAd activity, leading us to pursue the experiments with the CRAd lacking the E3 region. The detrimental effect of the entire E3 region was consistent with previous data showing that the E3 products $14.5 \mathrm{~K}$ and $10.4 \mathrm{~K}$ down-regulated E1A at the translational level (41). However, more recent evidence indicates that restoration of the $\mathrm{E} 3$ adenoviral death protein or even the entire E3 coding region might enhance CRAd activity $(42-44)$, strongly suggesting that AV22EL lytic activity could be greatly improved by adding the adenoviral death protein coding region without losing tumor specificity.

To assess the potential capacity of AV22EL as a therapeutic agent in the clinics, we studied its combination with 5-FU that remains the mainstay of treatment for metastatic CRC. We did different combinations in vitro to establish $(a)$ whether both compounds can result in additive or synergistic therapeutic effect, $(b)$ if this effect might depend on the administration timing of both compounds, and $(c)$ if they might render resistant cells sensitive to their combination. We observed that the combination of AV22EL and 5-FU was strongly effective in vitro even at concentrations where they were less effective as single agents. This improved in vitro inhibitory effect was observed in three different colon cancer cell types that differed in their A33 expression levels, mainly when the virus was administered before the chemotherapeutic agent, indicating that the virus was permissive for 5-FU effect. Despite the fact that we were unable to see enhanced therapeutic effect in vivo of their combination, the whole studies suggest that AV22EL can potentially induce an additive effect in combination with 5-FU against both p53 mutant (HT29 and T84) and WT (LoVo) colon carcinoma cells. This is of high importance as the cell cycle response to 5-FU treatment in colorectal carcinoma cells has been reported to be influenced by p53 status (45). It is expected that the therapeutic efficacy of AV22EL can be further improved by assessing different combination protocols with 5-FU or additional novel chemotherapeutic agents.

Liver metastases remain a significant clinical problem in CRC with limited therapeutic options. Few oncolytic vectors were systemically administered to target hepatic metastasis derived from CRC. Systemic administration of AV22EL induced the disappearance of metastatic nodules in $>90 \%$ of mice and seemed to restore normal levels of hepatic enzymes. Moreover, human hepatocytes were completely refractory to AV22EL and autopsy done on mice that received AV22EL systemically confirmed the absence of hepatic toxicity. Because murine cells are not permissive for adenoviral replication, it was of relevance in terms of viral toxicity the information obtained from the use of Onyx-15 in the clinics, a type 5 oncolytic adenovirus that is attenuated due to the deletion in E1b 55K gene (46). Recent data show that its administration through the hepatic artery to patients with metastatic CRC involving the liver exerted only minimal toxicity (47). Because fresh human CRC samples exhibited high expression levels of coxsackie-adenoviral receptor, the natural receptor of adenovirus type 5 (48), it can be proposed that oncolytic viruses based on adenovirus type 5 with strong and selective lytic capacity, such as AV22EL, which is highly attenuated in hepatic cells, might represent an alternative to existing oncolytic viruses for systemic administration.

The human A33 antigen is a $M_{\mathrm{I}} 43,000$ cell membrane glycoprotein that has become a target for antibody immunotherapy due to its restricted localization in colon cancer as well as in metastatic lesions of the same origin (24). The humanized antibody (huA33) has led to the initiation of a phase I clinical trials with encouraging results (26). The iodinated antibody has shown selective localization and deep penetration even in large necrotic tumors, suggesting that huA33 might become a therapeutic tool for cancer immunotherapy (24). However, in two clinical studies, patients developed anti-huA33 antibodies, limiting its potential therapeutic effect and the full manifestation of its potential clinical toxicities $(49,50)$, 
A
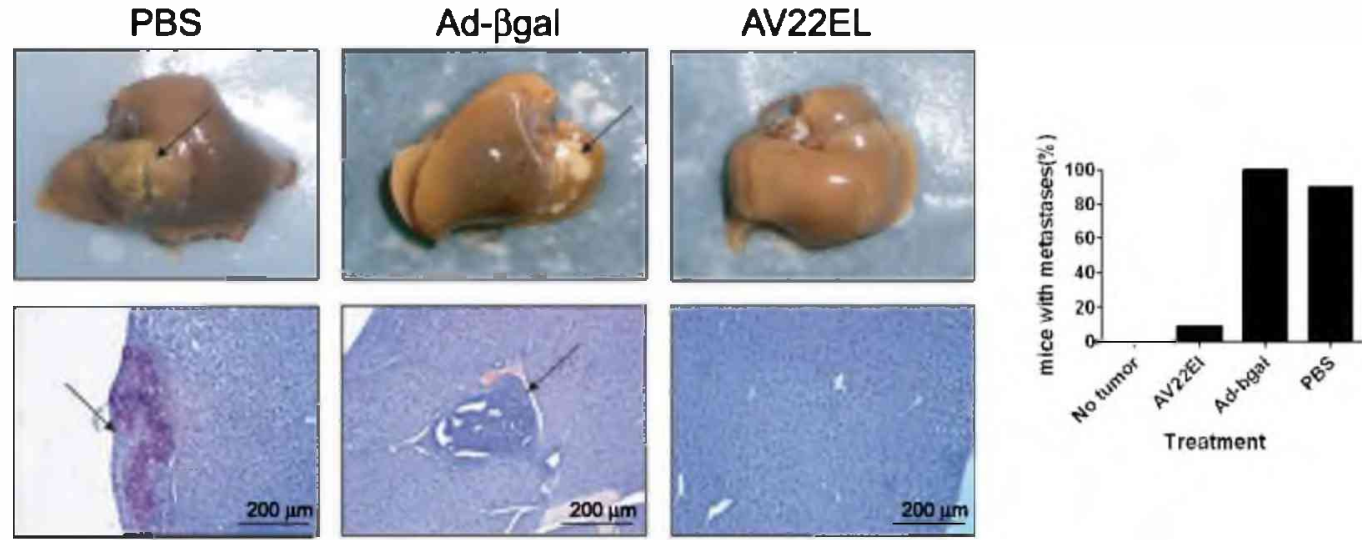

B

AV22EL
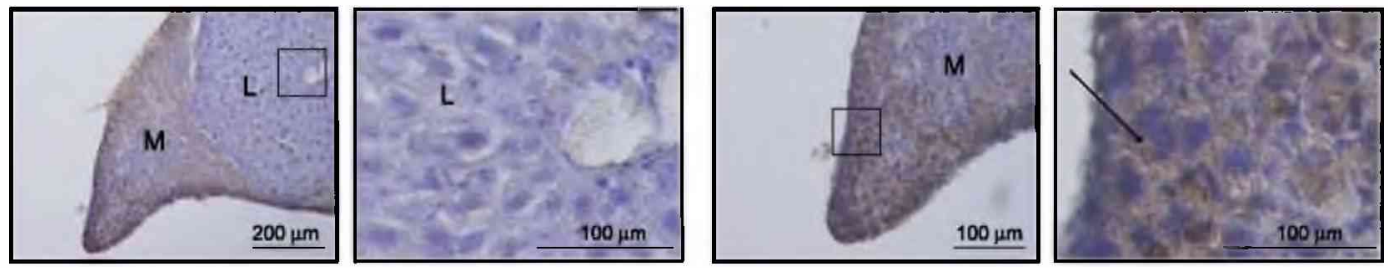

C

AV22EL

PBS
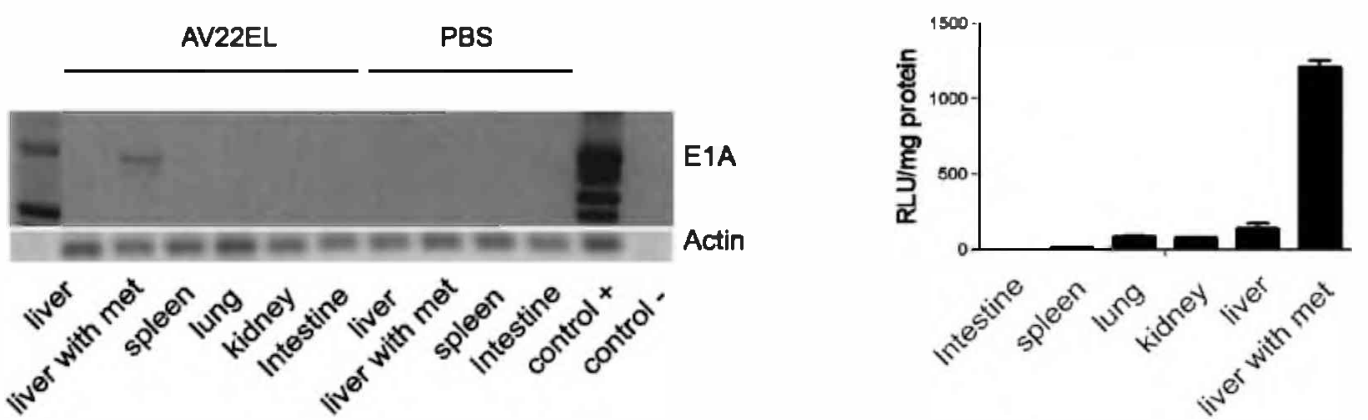

D
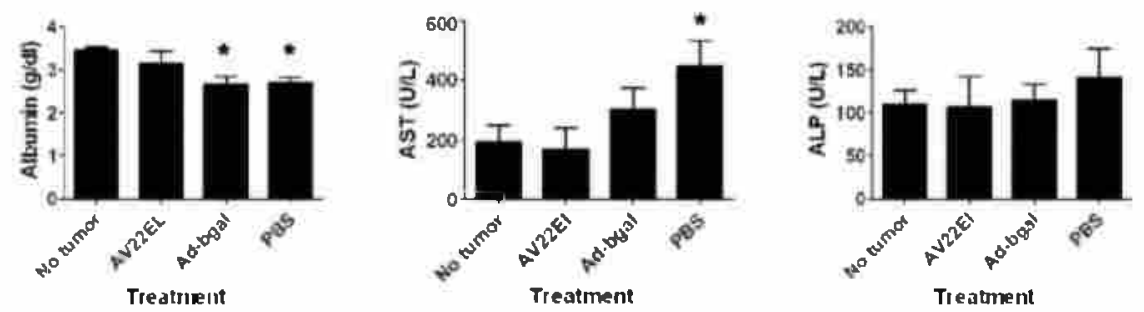

Fig. 6. In vivo efficacy of AV22EL on established hepatic metastases. A, representative photographs of mice carrying LoVo tumors treated or not with AV22EL. Arrow, light macroscopic photographs showing the presence of metastatic nodules in PBS-treated and Ad-Bgal-treated mice. Top, AV22EL-treated mice show the liver clear of metastatic nodules. H\&E staining of human liver sections. Bottom, arrows, LoVo tumors display areas with glandular-like arrangement of tumor cells. Magnification, $\times 200$. Right, comparison of metastases number. Number of metastases were determined at the end of the experiments $14 \mathrm{~d}$ after administration of the first viral dase. $B$, immunohistochemical detection of hexon protein in metastatic areas $(M)$ located in the liver $(L)$. Arrows, positive staining in metastatic cells and negative staining in hepatocytes. The areas in the box are further examined at higher magnification. Magnifications, $\times 200$ and $\times 400$. $C$, E1A mRNA expression in different organs following AV22EL administration. PCR analysis was done on total RNAs obtained from different organs $72 \mathrm{~h}$ after injection of AV22EL or PBS via tail vein. Right, tissue distribution of AV-Luc. Six mice were administered i.v. $10^{10}$ vp of AV-Luc and $10^{z}$ vp of Ad-CMV Renilla. Forty-eight hours later, luciferase activity in variaus tissues and liver metastatic nodules was determined. Results are expressed as mean of luciferase activity in light units per milligram of protein. Bars, SD. $D$, camparison of serum liver chemistries: hepatic panel function was determined at the end of the experiments $14 \mathrm{~d}$ after administration of the first viral dose. Serum enzyme levels are reported in units/mL. Albumin level is reported in $\mathrm{g} / \mathrm{dL}$. Columns, mean; bars, SD. *, statistically significant differences to no tumor mice $(P<0.05)$.

suggesting that a less immunogenic compound might be necessary.

Here, we have shown the therapeutic efficacy of a novel CRAd whose replication is driven by the A33 promoter, providing an additional strategy that makes use of the tissuespecific expression of this protein. Despite the fact that AV22EL exhibited lower replication capacity than WT adenovirus in vitro, it showed intratumor replicating capacity similar to 
that attained in breast cancer for a CRAd that targets the $\mathrm{G}_{1}-\mathrm{S}$ checkpoint (Ad-d1922-947) and higher than Ad-Onyx-017 that targets p53 (36). Thus, AV22EL was highly effective on primary tumors and hepatic metastasis of CRC with no cytocidal effect on normal colon derived cells, could be combined with current chemotherapeutic treatments, restored the normal hepatic function after the elimination of hepatic metastasis, and after systemic administration was strictly active in hepatic metastases, avoiding normal organs. Given the evidence of the mild adverse effects of oncolytic adenovirus therapeutics, we believe that AV22EL might become a useful tool for treatment of patients with CRC.

\section{Disclosure of Potential Conflicts of Interest}

No potential conflicts of interest were disclosed.

\section{Acknowledgments}

We thank Flarencia Straminsky and Fabio Fraga for their technical support

\section{References}

1. Elias D, Liberale G, Vernerey D, et al. Hepatic and extrahepatic colarectal metastases: when resectable their localization does not matter, but their total number has a prognestic effect. Ann Surg Oncal 2005;12: 900-9.

2. Lorenz M, Staib-Sebler E, Hochmuth K, et al. Surgical resection of liver metastases of colorectal carcinoma: short and long-term results. Semin Oncol 2000 27:112-9.

3. Meyerhardt JA, Mayer RJ. Systemic therapy for colorectal cancer. N Engl J Med 2005;352:476-87.

4. Rothenberg ML, Oza AM, Bigelow RH, et al. Superiority of oxaliplatin and flucrouracil-|eucovorin campared with either therapy alone in patients with progressive colorectal cancer after irinotecan and f uorouracil-leucovorin: interim results of a phase III trial. J Clin Oncol 2003;21:2059-69.

5. Rougier P, Bugat $R$, Douillard JY, et al. Phase II study of irinotecan in the treatment of advanced colorectal cancer in chemotherapy-naive patients and patients pretreated with flucrouracil-based chemotherapy. J Clin Oncol 1997:15:251-60.

6. Rougier P, Van Cutsem E, Bajetta E, et al. Randomised trial of irinotecan versus f luorouracil by continu ous infusion after flucrouracil failure in patients with metastatic calorectal cancer. Lancet 1998;352:1407-12.

7. Past DE, Van Meir EG. A novel hypoxia-inducible factor (HIF) activated oncolytic adenovirus for cancer therapy. Oncogene 2003;22:2065-72.

8. Yu DC, Working P, Ando D. Selectively replicating oncolytic adenoviruses as cancer therapeutics. Cur Opin Mol Ther 2002;4:435-43.

9. Bauerschmitz GJ, Guse K, Kanerva A, et al. Tripletargeted ancalytic adenoviruses featuring the cox2 promoter, E1A transcamplementatian, and serotype chimerism for enhanced selectivity for ovarian cancer cells. Mol Ther 2006;14:164-74.

10. Li Y, Chen Y, Dilley J, et al. Carcincembryonic antigen-producing cell-specific ancolytic adenovirus, OV798, for calarectal cancer therapy. Mol Cancer Ther 2003;2:1003-9.

11. Dabrowska A, Szary J, Kowalczuk M, Szala S, Ugorski M. CEA-negative glioblastoma and melanoma cells are sensitive to cytosine deaminase/5-fluaracytosine therapy directed by the carcinoembryonic ant gen promater. Acta Biachim Pol 2004;51:723-32.

12. Qiao J, Doubrovin M, Sauter BV, et al. Tumor-specific transcriptional targeting of suicide gene therapy. GeneTher 2002;9:168-75

13. Yamamoto $M$, Davydova J, Wang $M$, et al. Infectivity enhanced, cyclocxygenase-2 promoter-based conditianally replicative adenovirus for pancreatic cancer. Gastroenteralogy 2003;125:1203-18.

14. Irving J, Wang $Z$, Powell S, et al. Conditionally replicative adenovirus driven by the human telomerase promoter provides broad-spectrum antitumar activity without liver taxicity. Cancer Gene Ther 2004:11: $174-85$.

15. Shirakawa T, Hamada K, Zhang Z, et al. A cox-2 promoter-based replication-selective adenoviral vector to target the cox-2-expressing human bladder cancer cells. Clin Cancer Res 2004:10:4342-8.
16. Homicsko K, Lukashev A, lggo RD. RAD001 (everolimus) improves the efficacy of replicating adenoviruses that target colon cancer. Cancer Res 2005;65: $6882-90$.

17. Lu ZZ, Ni F, Hu ZB, et al. Efficient gene transfer into hematopoietic cells by a retargeting adenoviral vector system with a chimeric fiber of adenovirus seratype 5 and 11p. Exp Hematcl 2006;34:1171 -82.

18. Staff A, Rivera AA, Baneriee NS, et al. Strategies to enhance transductional efficiency of adenoviral-based gene transfer to primary human fibroblasts and keratinocytes as a platform in dermal wounds. Wound Repair Regen 2006:14:608-17.

19. Heath JK, White SJ, Jahnstone CN, et al. The human A33 antigen is a transmembrane glycoprotein and a novel member of the immunoglobulin superfamily. Proc Natl Acad Sci U S A 1997;94:469 - 74

20. Sakamoto J, Kojima $\mathbf{H}$, Kato J, Hamashima $\mathbf{H}$ Suzuki H. Organ-specific expression of the intestina epithelium-related antigen A33, a cell surface target for antibody-based imaging and treatment in gastrointestinal cancer. Cancer Chemother Pharmacal 2000. 46 Suppl:S27-32.

21. Moss A, Daran P, MacMathuna P. In silico promoter analysis can predict genes of functional relevance in cell proliferation: validation in a colon cancer model. Translational Oncogenomics 2007;2:1 - 16 .

22. Almqvist $Y$, Steffen $A C$, Lundqvist $H$, Jensen $H$, Tolmachev V, Sundin A. Biodistribution of 211A1labeled humanized monaclanal antibody A33. Cancer Bic ther Radiopharm 2007:22:480-7.

23. King DJ, Antaniw P, Owens RJ, et al. Preparation and preclinical evaluation of humanised A33 immuno conjugates for radioimmunotherapy. $\mathrm{Br} J$ Cancer 1995; 72:1364-72

24. Scott AM, Lee FT, Jones $R$, et al. A phase I trial of humanized monoclonal antibody $A 33$ in patients with colorectal carcinoma: biodistribution, pharmacokinetics, and quantitative tumar uptake. Clin Cancer Res 2005:11:4810-7.

25. Welt S, Divgi CR, Real FX, et al. Quantitative analysis of antibody localization in human metastatic calon cancer: a phase I study of monoclanal antibody $\mathrm{A} 33$. $\mathrm{J}$ Clin Oncol 1990;8:1894-906.

26. Welt S, Ritter G, Williams C Jr, et al. Phase I study of anticalon cancer humanized antibody A33. Clin Cancer Res 2003;9:1338-46.

27. Kanerva A, Hemminki A. Adenoviruses for treatment of cancer. Ann Med 2005;37:33-43.

28. Jakubczak JL, Ryan P, Gorziglia M, et al. An oncolytic adenovirus selective for retinoblastoma tumor suppressor protein pathway-defective tumors: dependence on E1A the E2F-1 promoter, and viral replication for selectivity and efficacy. Cancer Res 2003:63: $1490-9$

29. Martin-Duque $P$, Jezzard $S$, Kaftansis L, Vassaux G. Direct comparison of the insulating properties of two genetic elements in an adenoviral vector containing two different expressian cassettes. Hum Gene Ther 2004:15:995-1002

30. Bett AJ, Haddara W, Prevec L, Graham FL. An efficient and f exible system for construction of adenovi- rus vectors with insertions or deletions in ear y regions 1 and 3. Proc Natl Acad Sci U S A 1994;91:8802-6. 31. Lieber A, He CY, Kirillova I, Kay MA. Recombinant adenoviruses with large deletions generated by Cremediated excision exhibit different biological properties compared with first-generation vectors in vitro and in vivo. J Viral 1996:70:8944-60.

32. Tang DC, Jahnston SA, Carbone DP. Butyrateinducible and tumar-restricted gene expression by adenovirus vectors. Cancer GeneTher 1994:1:15-20. 33. Vondran FW, Katenz E, Schwartlander R, et al. Isolation of primary human hepatocytes after partial hepatectomy: criteria for identification of the most promising liver specimen. Artif Organs 2008;32: $205-13$.

34. Lopez MV, Blanco P, Viale DL, et al. Expression of a suicidal gene under contral of the human secreted protein acidic and rich in cysteine (SPARC) promoter in tumor or stromal cells led to the inhibition of tumor cell grawth. Mol CancerTher 2006;5:2503-11.

35. Li Y, Yu DC, Chen Y, et al. A hepatocellular carcinoma-specific adenovirus variant, CV890, eliminates distant human liver tumors in combination with daxarubicin. Cancer Res 2001;61:6428-36.

36. Bazan-Peregrino M, Carlisle RC, HernandezAlcoceba R, et al. Comparison of molecular strategies for breast cancer virotherapy using oncolytic adenovirus. Hum GeneTher 2008;19:873-86.

37. Bazan-Peregrino M, Carlisle RC, Purdie L, Seymaur $L W$. Factors influencing retention of adenovirus within tumaurs following direct intratumaural injection. Gene Ther 2008;15:688-94

38. Hoffmann D, Wildner O. Efficient generation of double heteralogous promater controlled oncolytic adenovirus vectars by a single hamolagous recombination step in Escherichia coli. BMC Biotechnal 2006:6:36

39. Sava P, Ren XW, Ni S, et al. A tumor-targeted and conditionally replicating oncolytic adenovirus vector expressing TRAIL for treatment of liver metastases. MolTher 2004;9:496-509.

40. McGrory WJ, Bautista DS, Graham FL. A simple technique for the rescue of early region I mutations into infectious human adenovirus type 5 . Virology 1988 163:614-7.

41. Zhang X, Bellett AJ, Hla RT, Voss T, Mullbacher A, Braithwaite AW. Down-regulation of human adenovirus Ela by E3 gene products: evidence for trans ational cantrol of E1a by E3 $14.5 \mathrm{~K}$ and/or E3 $10.4 \mathrm{~K}$ products. $J$ Gen Viral 1994;75:1943-51.

42. Danielssan A, Dzojic H, Nilsson B, Essand M. Increased therapeutic efficacy of the prostate-specific oncolytic adenovirus $\mathrm{Ad}$ (I/PPT-E1A) by reduction of the insulator size and introduction of the full-length E3 regian. Cancer GeneTher 2008;15:203-13.

43. Shashkova EV, Kuppuswamy MN, Wald WS Doronin K. Anticancer activity of oncalytic adencvirus vector armed with IFN- $\alpha$ and ADP is enhanced by pharmacologically controlled expression of TRAIL. Cancer GeneTher 2008:15:61 - 72

44. Yun CO, Kim E, Koo T, Kim H, Lee YS, Kim JH. ADP-overexpressing adenovirus elicits enhanced 
cytopathic effect by induction of apoptosis. Cancer Gene Ther 2005;12:61 - 71.

45. Petersen S, Thames HD, Nieder C, Petersen C Baumann $\mathrm{M}$. The results of calorectal cancer treatment by p53 status: treatment-specific overview. Dis Calan Rectum 2001:44:322-33; discussion $333-4$

46. Heise C, Sampson-Johannes A, Williams A, McCormick F, Von Hoff DD, Kirn DH. ONYX-015, an E1B gene-attenuated adenovirus, causes tumorspecific cytolysis and antitumoral efficacy that can be augmented by standard chemotherapeutic agents. Nat Med 1997:3:639-45.

47. Au T, Tharne S, Karn WM, Sze D, Kirn D, Reid TR. Minimal hepatic toxicity of Onyx-015: spatial restriction of coxsackie-adenoviral receptor in normal liver. Cancer GeneTher 2007:14:139-50.

48. Wulff $\mathrm{H}$, Krieger T, Kruger $\mathrm{K}$, ef al. Cloning and characterization of an adenoviral vector for highly efficient and doxycycline-suppressible expression of bioactive human single-chain interleukin 12 in colon cancer. BMC Biotechno| 2007:7:35.
49. Ritter G, Cohen LS, Williams C, Jr. Richards EC Old LJ, Welt $S$. Serolagical analysis of human anti-human antibody responses in colon cancer patients treated with repeated doses of humanized manoclanal antibody A33. Cancer Res 2001;61: $6851-9$.

50. Welt S, Ritter G, Williams C Jr, et al. Preliminary report of a phase I study of combination chemotherapy and humanized $\mathrm{A} 33$ antibody immunotherapy in patients with advanced colorectal cancer. Clin Cancer Res 2003;9:1347-53. 


\section{Clinical Cancer Research}

\section{A Novel A33 Promoter-Based Conditionally Replicative Adenovirus Suppresses Tumor Growth and Eradicates Hepatic Metastases in Human Colon Cancer Models}

Eduardo G. Cafferata, Daniela R. Macció, Maria V. Lopez, et al.

Clin Cancer Res 2009;15:3037-3049.

Updated version Access the most recent version of this article at:

http://clincancerres. aacrjournals.org/content/15/9/3037

Supplementary Access the most recent supplemental material at:

Material http://clincancerres.aacrjournals.org/content/suppl/2009/04/01/1078-0432.CCR-08-1161.DC1

Cited articles This article cites 50 articles, 16 of which you can access for free at:

http://clincancerres. aacrjournals.org/content/15/9/3037.full\#ref-list-1

Citing articles This article has been cited by 1 HighWire-hosted articles. Access the articles at:

http://clincancerres. aacrjournals.org/content/15/9/3037.full\#related-urls

E-mail alerts Sign up to receive free email-alerts related to this article or journal.

Reprints and To order reprints of this article or to subscribe to the journal, contact the AACR Publications

Subscriptions Department at pubs@aacr.org.

Permissions To request permission to re-use all or part of this article, use this link http://clincancerres. aacrjournals.org/content/15/9/3037.

Click on "Request Permissions" which will take you to the Copyright Clearance Center's (CCC)

Rightslink site. 